\title{
Facilitating claims settlement using building information modeling in the school building projects
}

\author{
Rehab Abdul Razzaq Ibraheem ${ }^{1}$. Ahmed Mohammed Raoof Mahjoob ${ }^{1}$
}

Received: 26 April 2021 / Accepted: 6 September 2021 / Published online: 12 October 2021

(c) Springer Nature Switzerland AG 2021

\begin{abstract}
Claims have a lot of space in construction projects, as they can have a considerable monetary value and thus negatively affect the final amount and duration of the project. This study seeks to suggest a building information modeling (BIM) approach to reduce most of the root causes of claims during the design phase. Thus, claims can be reduced during the project implementation phase. A questionnaire form was designed and distributed to 28 experts to obtain expert opinions on construction claims' most important causes. In return, data were collected for 128 projects in Iraq, and the reasons for claims were extracted from them. After making the match between experts' opinions and real projects, it was found that the match rate is high and that there are sixteen critical reasons for construction claims in Iraqi projects. After matching these causes with the BIM functions, a flowchart of each cause is drawn, and the inputs, tools, and outputs of the process are identified. The results showed the ability of BIM to prevent eight significant causes of claims (inaccurate quantities, excessive change orders, errors and design changes, flaws in drawings and specifications, and poor coordination between designers (structural, architectural, MEP)) through these BIM functions (3D visualization, clash detection, coordination, and take-off). The main results applied to a realistic case study show that BIM technology can be used as a precautionary approach during the design stage to reduce claims during implementation by $(55.2 \%)$ so that the functions of this technology can solve the fundamental causes of claims in the construction projects sector in Iraq.
\end{abstract}

Keywords Claims $\cdot$ BIM $\cdot$ Construction projects $\cdot$ Design phase

\section{Introduction}

The construction projects' complex environment, unconfirmed and multi-lateral, has made these projects suffer from the difficulty of completing them within the work progress schedule set for them. The proliferation of complex construction projects has become widely available recently due to many requirements and changes of the business owner and the emergence of modern technological technologies and the required standards significantly. For this reason, the construction industries are considered one of the methods leading to claims between the parties.

Rehab Abdul Razzaq Ibraheem

r.razzaq1101@ coeng.uobaghdad.edu.iq

Ahmed Mohammed Raoof Mahjoob

ahmed.mahjoob@coeng.uobaghdad.edu.iq

1 Construction Project Management, Civil Engineering Department, College of Engineering, University of Baghdad, Baghdad, Iraq
Claims are a group of events that occur during the construction process and result in an additional cost or time extension for the project [1]. The claim can also be described as a legitimate request to obtain compensation, whether financial or time or both, due to changes in terms of the contract stipulated previously [2]. Claims arise for a large number of reasons, through which claims can be categorized into different types. Participants in the project (owner, consultant, contractor, and others) are responsible for the occurrence of claims [3]. Most of the additional periods and excess costs in construction projects result from claims between the parties. A comprehensive analysis of the claims' impact indicated that the cost and duration of the project exceeded between (10\%-25\%) (25-50\%), respectively [4].

Moreover, the cost of disputes is estimated from 0.5 to 5 of the project's total cost [5]. These claims negatively affect all partners. Thus, a framework used in managing the construction claims reduces each party's damage [6]. Early claims resolution is essential to maintain relationships between participants because delaying conflict resolution 
and not knowing the result of this dispute inevitably leads to the project's remaining activities' low quality [2]. The increasing conflicts in construction projects indicate the inefficiency of the methods used in managing construction claims, despite the intensification of research studies' efforts to devise these methods [7]. Using advanced technologies by construction industries leads to preventing or reducing claims, it requires converting the traditional system into a digital environment for efficient processing, one of the most recent methods that have emerged in recent years is using a building information modeling approach where most building engineers believe is the best way to reduce claims [8]. Besides, BIM is a useful tool in managing multiple aspects of projects, including managing construction claims [9]. The application of BIM technology will lead to the design, construction, and delivery of more sustainable projects in Iraqi projects, by reviewing the most important benefits of this technology [10].

Most building engineers believe that the best way to reduce claims is to use a BIM approach, and it has not already been applied to a real case study. To mitigate the impact of claims, increased attention must be paid to pre-implementation stages, including accuracy in drawings, designs, and documentation. For the purpose of this research, the following definition will be adopted, BIM is a set of coordinated processes that increase the productivity of the project so that the change in any part is applied to all other parts of the model and thus will reduce the time and cost of the project. The main aim of this paper is summarized by using the (BIM) approach to predict and resolve these claims during the design phase before they occur in the construction phase. To achieve this goal first the causes of the claim must be identified by matching between the theoretical causes, from reviewing the previous studies, and real causes, by studying 128 real projects. After identifying the causes of the main claim, the BIM function will be investigated to select the suitable ones that can be used in claim reduction. To test the selected BIM function in claim reduction, a real case study project was selected to apply these functions and analyze the results. Finally, a set of conclusions were extracted from this study.

\section{Research justification}

Claims in the construction sector play an important role in delaying project completion and exceeding the final total cost. Therefore, it must be studied in detail. The justifications for the research can be explained as follows:

- The increase in the size and complexity of construction projects requires good knowledge of the causes of claims to reduce them and control of their effects.
- The use of traditional methods in managing claims for existing buildings in Iraq led to the failure to complete the project within the period and cost overrun. Therefore, there is a need to use modern tools in managing construction claims.

- The construction industry in the world has witnessed a great development in BIM technology, characterized by accurate quantification, understanding project requirements, and reducing change orders by linking the 3D model to reality.

\section{Research hypothesis}

The basic hypothesis of this study assumes (the existence of weakness in the system applied to reduce construction claims in most construction sector projects in Iraq with no clear methods of identifying the root causes and the sources causing those claims during the five stages of the project life cycle). Moreover, the roots of the claim could be solved by using BIM methodology.

\section{Research limitation}

There are great difficulties in obtaining the necessary documents for the study due to the coronavirus disease (COVID19). Furthermore, some secret documents are difficult to inspect, particularly for the designer.

\section{Methodology of research}

The methodology of this research had implemented by applying the following stage:

\section{Causes of claims}

Claims arise for a large number of reasons, through which claims can be categorized into different types. It is not possible to eliminate claims in construction projects despite the suggestion of many methods and procedures to prevent their occurrence. Therefore, no project can be devoid of them. [11] Classified the claims into six types and six groups. While $[3,12]$ ranked the causes of disputes into five roots: the client, the contractor, the consultant, contractual terms, design defects, and implementation processes. In Malaysia [13], the most common causes of claims suffered by contractors and consultants are many changes in design during implementation. In Taiwan [14], conflict types and solutions are classified for Public-Private Partnership (PPP). The most frequent causes of claims in Iraqi construction projects are determined in this stage as follow: 


\section{Theoretical study}

The data were collected through studying and analyzing the previous literature to collect information about the causes of claims and classify them according to their sources. These data were collected from multiple sources such as books, articles, international conferences, and all the websites available on the internet. Four matrices were designed that include the reasons for building claims for each source during the life cycle of the project is explained as (owner, consultant, contractor, and external factors).

\section{Collecting data from opinions of experts}

In this phase, experts' needed to evaluate and review the matrices developed in the first stage related to the reasons for the theoretical side's claims. This phase consists of two stages, as follows:

1. Research sample The experts participating in responding to the questionnaire have practical experience managing construction projects to assess the causes of the most common claims in Iraqi projects. Twenty-eight questionnaires forms were distributed to the target research sample divided into five categories, as illustrated in Table 1.

The questionnaires forms were fully recovered, which were 28 questionnaires forms. After they were examined, one questionnaire was excluded due to the lack of fulfillment of the conditions required to answer the questionnaire. Thus, the number of questionnaires subject to the research has 27 questionnaires with a valid return rate for statistical analysis of $96.4 \%$. This large percentage reflects the interest of experts in construction claims. Thus, the sample results can be generalized to the research community since it represents an integral part of the construction industry's workers and influencers.

2. Close questionnaire The questionnaire is divided into two parts, as follows:

Part One-Personal information concerns the experts who participated in the survey, including gender, age,

Table 1 Expert's category list

\begin{tabular}{lll}
\hline Class of experts & $\begin{array}{l}\text { Number of respond- } \\
\text { ents }\end{array}$ & Percent \\
\hline Director general & 1 & 5.6 \\
Director of the department & 7 & 38.9 \\
Division officer & 6 & 16.7 \\
project manager & 9 & 16.7 \\
Site engineer & 5 & 22.2 \\
Total & 28 & 100 \\
\hline
\end{tabular}

name of the institution, type of work sector, engineering specialization, academic degree, years of experience, and projects executed. In addition to specifying the category to which the expert belongs, about their experiences in construction.

Part Two-Construction claims this part focuses on the causes of claims. These reasons are classified into four main categories; the questionnaire will ask the experts to explain their perceptions about the degree of recurrence for each cause, which is chosen between five weights. The scale is (1: No, 2: Rarely, 3: Sometimes, 4: Mostly, 5: Always). The data were analyzed using the SPSS statistical program.

\section{Collecting data from real projects in Iraq}

To determine the causes of claims in the construction projects, 128 projects data were collected from eight ministries, including (the Ministry of Planning, the Ministry of Oil, the Ministry of Electricity, the Ministry of Construction, Housing and Municipalities, the Ministry of Higher Education, the Ministry of Sports and Youth, the Ministry of Education and the Shiite Endowment). These projects were implemented in the period between 2004 and 2019. The projects were reviewed from the feasibility study stage to the end of the implementation stage. The project was handed over to the employer; the developments and changes in the project were tracked. After reviewing the project files, four main categories were extracted with reasons that led to raising claims during each of these projects' life cycles.

\section{Data matching and determine the most frequent reasons of claims in Iraqi construction projects}

This stage includes finding the match between experts' opinions and the real projects to get the causes of each source's claims during the Iraqi project life cycle. The most frequent identical reasons for Iraqi construction projects' claims were determined [15].

\section{Application of the BIM mechanism in a real case study}

The BIM functions will be applied to the project (building a school containing 18 classrooms) to achieve the research's intended purpose as following:

- The functions and features of BIM technology are examined according to the previous literature.

- Determining the BIM functions matches the reasons to reduce the claim before it occurs. 
- The research goal is achieved through a detailed explanation and schematic drawing for each function of BIM techniques capable of solving the claim's cause to serve as an approach to managing construction claims in the Iraqi projects sector.

The research methodology is summarized and presented in Fig. 1 .

\section{Reasons for construction claims}

The results showed sixteen main reasons that led to the occurrence of claims in the Iraqi construction projects. They are related to three categories (owner, contractor, and consultant), as shown in Table 2.

\section{BIM-Based construction claims management system in Iraq}

\section{BIM functions with causes of claims}

The results of matching BIM functions with building claims demonstrated the capabilities of BIM in reducing eight out of a total of sixteen causes, as shown in Table 3.

The responsibility for accuracy using the BIM functions is the responsibility of the designer depending on:

- Correct modeling of building elements.

- Accuracy of the project information that meets the owner's requirements.

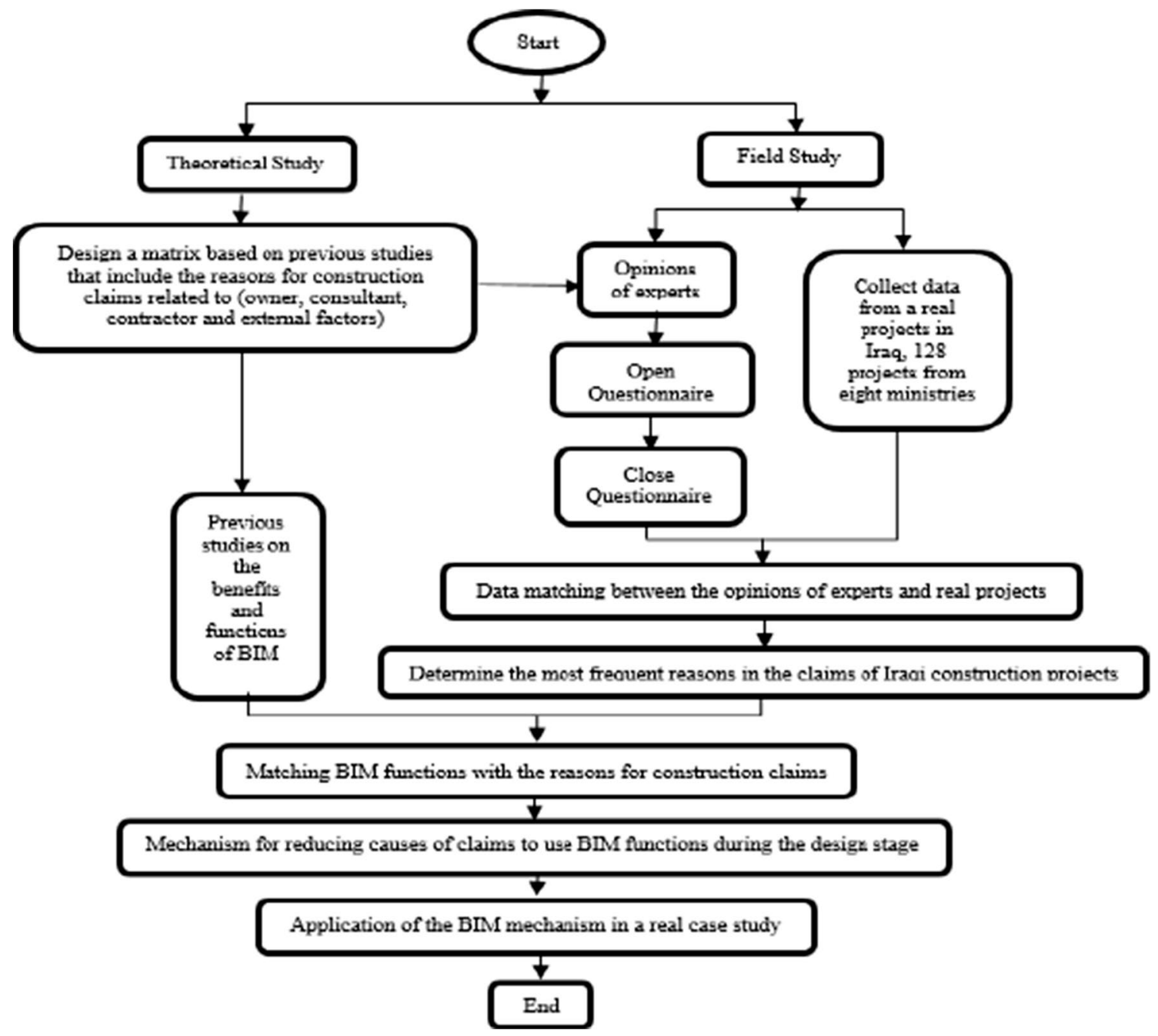

Fig. 1 Research methodology 
Table 2 The main causes of claims in Iraqi construction projects

\begin{tabular}{|c|c|c|c|c|}
\hline Causes of claims & Rate\% & Rank & Causative & Phase \\
\hline Inaccurate quantities & 76.4 & 1 & Consultant & Design \\
\hline Excessive change order by owner & 75.4 & 2 & Owner & Construction \\
\hline Design error or omissions & 74.8 & 3 & Consultant & Design \\
\hline Deficiency in drawing and specifications & 74.4 & 4 & Consultant & Design \\
\hline Refer the contract to the cheapest and least qualified contractor & 70.6 & 5 & Owner & Contracting \\
\hline Poor quality of contractor's work & 69.8 & 6 & Contractor & Construction \\
\hline Delay in payments to contractor and financial failure of the owner & 68.4 & 7 & Owner & Construction \\
\hline Poor qualifications, skills, and experience of the technical staff & 69.2 & 8 & Contractor & Construction \\
\hline Contractor financial problem & 68.7 & 9 & Contractor & Construction \\
\hline Poor site management and supervision by the contractor & 68.7 & 10 & Contractor & Construction \\
\hline $\begin{array}{l}\text { Poor communication and coordination between consulting engineers (struc- } \\
\text { tural, architectural,MEP) }\end{array}$ & 67.1 & 11 & Consultant & Design \\
\hline Design change by the owner & 65 & 12 & Owner & Design \\
\hline Variations between original and actual quantities & 63 & 13 & Consultant & Construction \\
\hline Non-conformity of specifications during implementation & 62.1 & 14 & Contractor & Construction \\
\hline Delay in payments to the consultant and financial failure of the owner & 61.5 & 15 & Owner & Design \\
\hline Design and specifications change & 61.2 & 16 & Consultant & Construction \\
\hline
\end{tabular}

Table 3 The ability of BIM functions to manage construction claims' causes during the design phase

\begin{tabular}{|c|c|c|c|}
\hline Cause of claim & BIM function & Causative & Phase \\
\hline 1. Inaccurate quantities & $\begin{array}{l}\text { 3D visualization } \\
\text { Clash detection } \\
\text { Coordination } \\
\text { Quantity takes off }\end{array}$ & Consultant & Design \\
\hline 2. Excessive change order by owner & $\begin{array}{l}\text { 3D visualization } \\
\text { Clash detection } \\
\text { Coordination } \\
\text { Collaboration }\end{array}$ & Owner & Construction \\
\hline 3. Design error or omissions & $\begin{array}{l}\text { 3D visualization } \\
\text { Clash detection } \\
\text { Coordination }\end{array}$ & Consultant & Design \\
\hline 4. Deficiency in drawing and specifications & $\begin{array}{l}\text { 3D visualization } \\
\text { Clash detection } \\
\text { Coordination }\end{array}$ & Consultant & Design \\
\hline $\begin{array}{l}\text { 5. Poor communication and coordination between con- } \\
\text { sulting engineers (structural, architectural, and MEP) }\end{array}$ & $\begin{array}{l}\text { 3D visualization } \\
\text { Clash detection } \\
\text { Coordination }\end{array}$ & Consultant & Design \\
\hline 6. Design change by the owner & $\begin{array}{l}\text { 3D visualization } \\
\text { Clash detection } \\
\text { Coordination } \\
\text { Collaboration }\end{array}$ & Owner & Design \\
\hline 7. Variations between original and actual quantities & $\begin{array}{l}\text { 3D visualization } \\
\text { Clash detection } \\
\text { Coordination } \\
\text { Quantity takes off }\end{array}$ & Consultant & Construction \\
\hline 8. Design and specifications change & $\begin{array}{l}\text { 3D visualization } \\
\text { Clash detection } \\
\text { Coordination }\end{array}$ & Consultant & Construction \\
\hline
\end{tabular}

Table 4 shows the inputs and outputs of merging the primary causes of claims with the BIM functions' proposed tool to reduce Iraq's construction claims.
A detailed explanation and diagrams of each cause are provided with the functions capabilities of reducing it during the project design stages to serve as a roadmap for a 
Table 4 Inputs, outputs, and BIM tools to reduce/prevent claims during the design phase

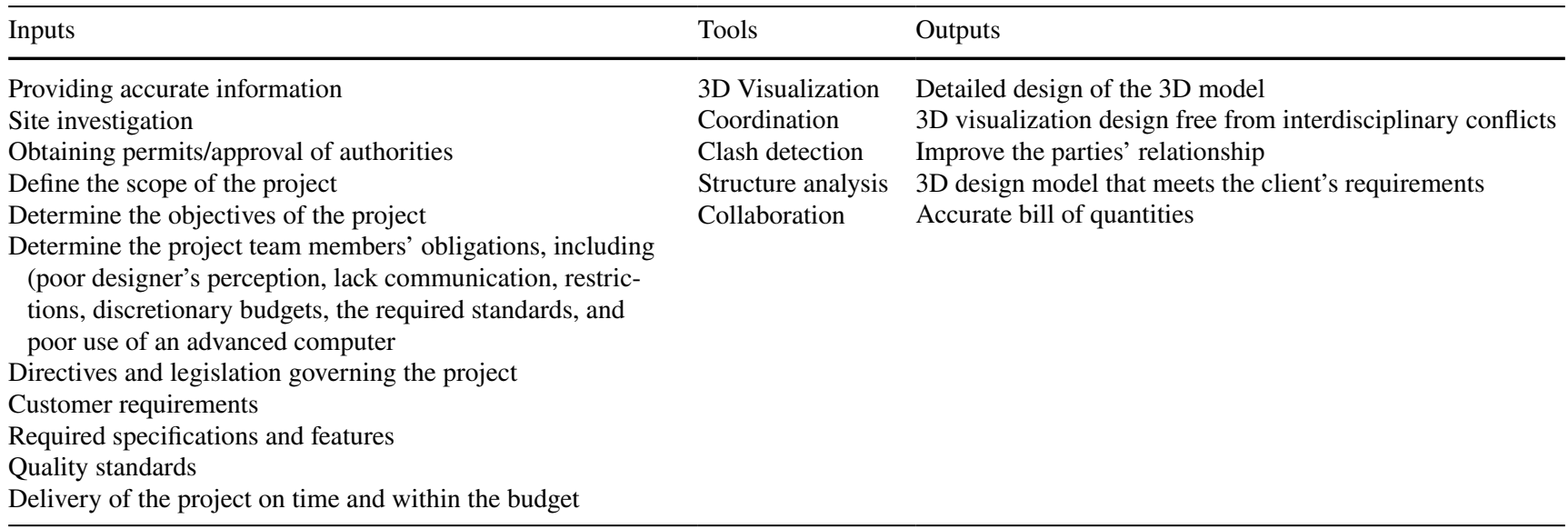

preventive approach to reduce the claim before it occurs as follows:

\section{BIM preventive approach for (deficiency in drawing and specifications), (design error or omissions), and (design and specifications change) by consultant}

Previous studies confirmed several causes that lead to errors in the design, drawings, or specifications. The functions and benefits of BIM can solve them. Figure 2 shows cause and effect based on the fishbone principle where (Cause) represents several features of BIM include: (clash detection, information and knowledge exchange, design coordination, communication, and constructability) that increase the productivity of the design process (Effect) based on BIM technology.

BIM systems provide an integrated software package model that allows knowledge and information exchange between designers to reduce/avoid design, drawing, and specification errors using Autodesk Revit, Navisworks to develop a 3D BIM model for the project, a system free from errors, omissions, and clashes.
The roles of BIM systems are similar to the role of the project manager in coordinating construction documents through the following functions:

- Creating a participatory approach facilitates access to building information and enables the design to be shared with the project parties at all stages.

- The ability to clash detection between project elements.

The so-called work set consists of building elements (walls, floors, columns, doors, electrical works, etc.), which gives each designer powers to add and modify his details, and none of the other users can work within his powers from the elements, which prevents conflicts between the elements. The different work set enables the coordination and publication of changes between designers. Through them, each user can update the changes by adding, deleting, or modify any building component that other users have made, thus ensuring good coordination.

Through a single model designed using BIM software, all the plans are created from (projections, interfaces, sections, details, scenes, and non-graphical data such as a table of quantities and properties of the elements). This means that the change in one chart is reflected in the rest of the schemes

Fig. 2 Fishbone diagram: adopting BIM technology to reduce design error

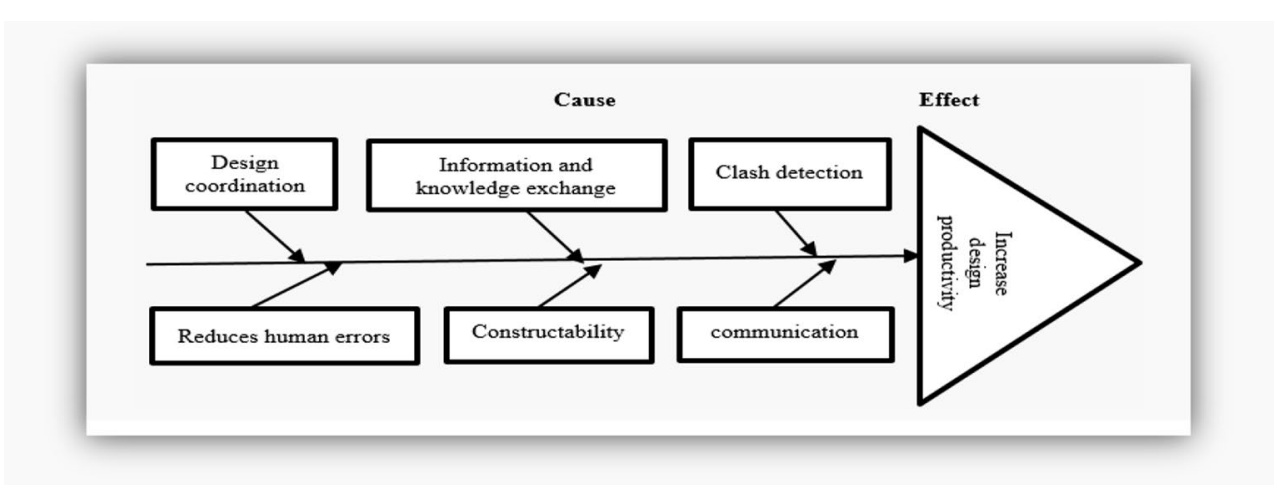


automatically and is called multi-directional linking (parametric objects), which saves a lot of time and contributes to eliminating human error or omission resulting from manual modification of all charts and quantities.

The primary source of changing the consultant's design and specifications during the construction phase is errors or omissions in the design phase. Previous studies have shown that BIM systems can reduce design errors that reduce changes in design or specifications during the implementation phase. Therefore, the consultant's BIM functions in solving design errors by the consultant during the design phase appear the same as those used in solving the design changes during the implementation phase. After completing the design process and overlaying all the building elements with a virtual structure that simulates reality, the clash detection feature can be activated to avoid conflicts and vacate them during the design phase before reaching the implementation. BIM mentioned above functions (coordination, 3D visualization, and clash detection) improve the design's constructability by providing multiple and fast solutions to solve design problems more realistically.

Figure 3 provides a diagram of the sequence of steps in making a $3 \mathrm{D}$ design model using BIM functions in the design phase and their outputs with high accuracy to reduce building prompts resulting from design errors or omissions, or defects in drawings and specifications during the design stage. Simultaneously, the design or specification changes by the designer during the construction phase will be mitigated.

\section{BIM preventive approach for poor communication and coordination between consulting engineers (structural, architectural, and MEP)}

Control of conflicts is one of the essential features of BIM systems. One of BIM technology's essential benefits is developing the coordination process through the automatic linking of project plans through the 3D model. Thus, the conflicts between the project parties are directly evident by linking the different disciplines (structural, architectural, and MEP), reducing project delivery delay, and not exceeding the budget. And clash detection functions identify collisions or interventions for multidisciplinary organisms.

Clash coordination is the process of solving those interventions to ensure maximum viability and functionality appropriate for those objects. The model update continues to perform analyzes using the (clash detection) function

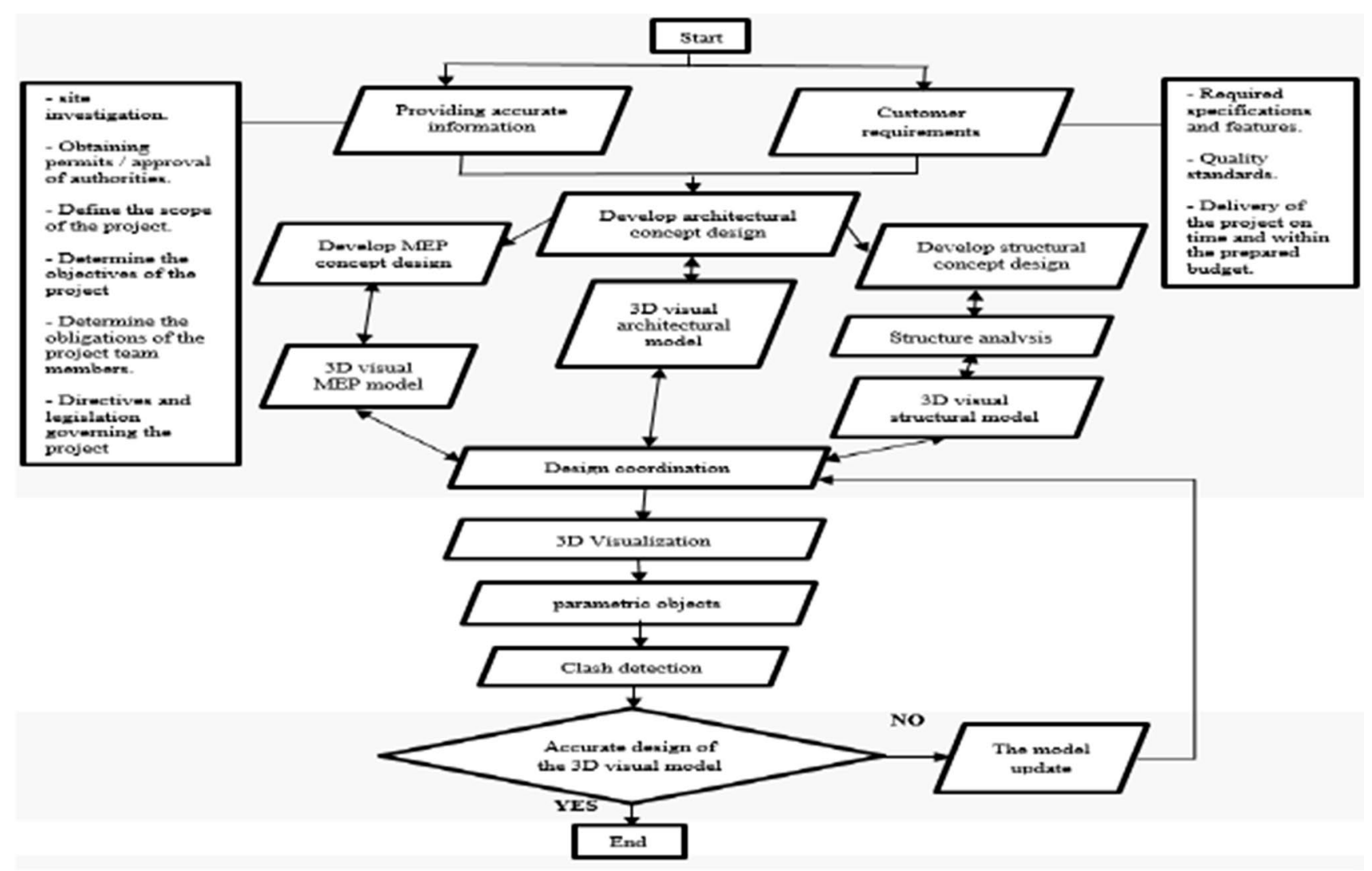

Fig. 3 The BIM design methodology to reduce (deficiency in drawing and specifications) (design error or omissions) (design and specifications change) 
that allows the discovery of conflicts between architectural, structural, and MEP works during the design phase.

Revit and Navisworks do these operations. Both programs help define the interactions in a 3D environment. With coordination and technical expertise in multiple disciplines, those conflicts are resolved to ensure the technical design's integrity and functionality.

Figure 4 provides a diagram of the sequence of steps in making a 3D design model using BIM functions in the design stage and their outputs with high accuracy to reduce construction claims resulting from conflicts between the designer's work (architectural, structural, and MEP).

\section{BIM preventive approach for (design change) and (excessive change order) by owner}

The design is a collective effort of a group of engineers, and this design must meet the needs of the owner and the laws in force and any restrictions placed on the construction process, all of this to achieve the owner's goals.

Change orders may be issued due to problems arising from the employer's lack of experience and giving contradictory or inconsistent instructions due to his willingness to change his technical specifications or make some changes to meet his needs and the project's target; clients have various capabilities to understand project CAD plans, even with some great potential for understanding. However, all this happens due to the poor perception of the owner. Having a 3D model or video display showing the structure's evolution over time helps the customer easily see and understand the constructor before implementing it on the ground.

The use of traditional systems using CAD schemes does not include reaching a feasible solution to link the plans, whether they belong to one specialty or several specialties or connect them with graphic information (specifications, quantities, characteristics, prices, etc.) as it depends on the creation of multiple schemes of the exact origin and is isolated from quantities and prices. Thus, it is not adequate to the extent required when any change occurs. Hence, the user resorts to updating a large group of charts and quantities associated with that bitter change that consumes excellent time and effort and is subject to error. While BIM creates a central database in which all the components of the building (plans, quantities, specifications, etc.) are stored in addition to their interconnectedness and thus, whatever the changes are, they are automatically reflected in the rest of the plans in

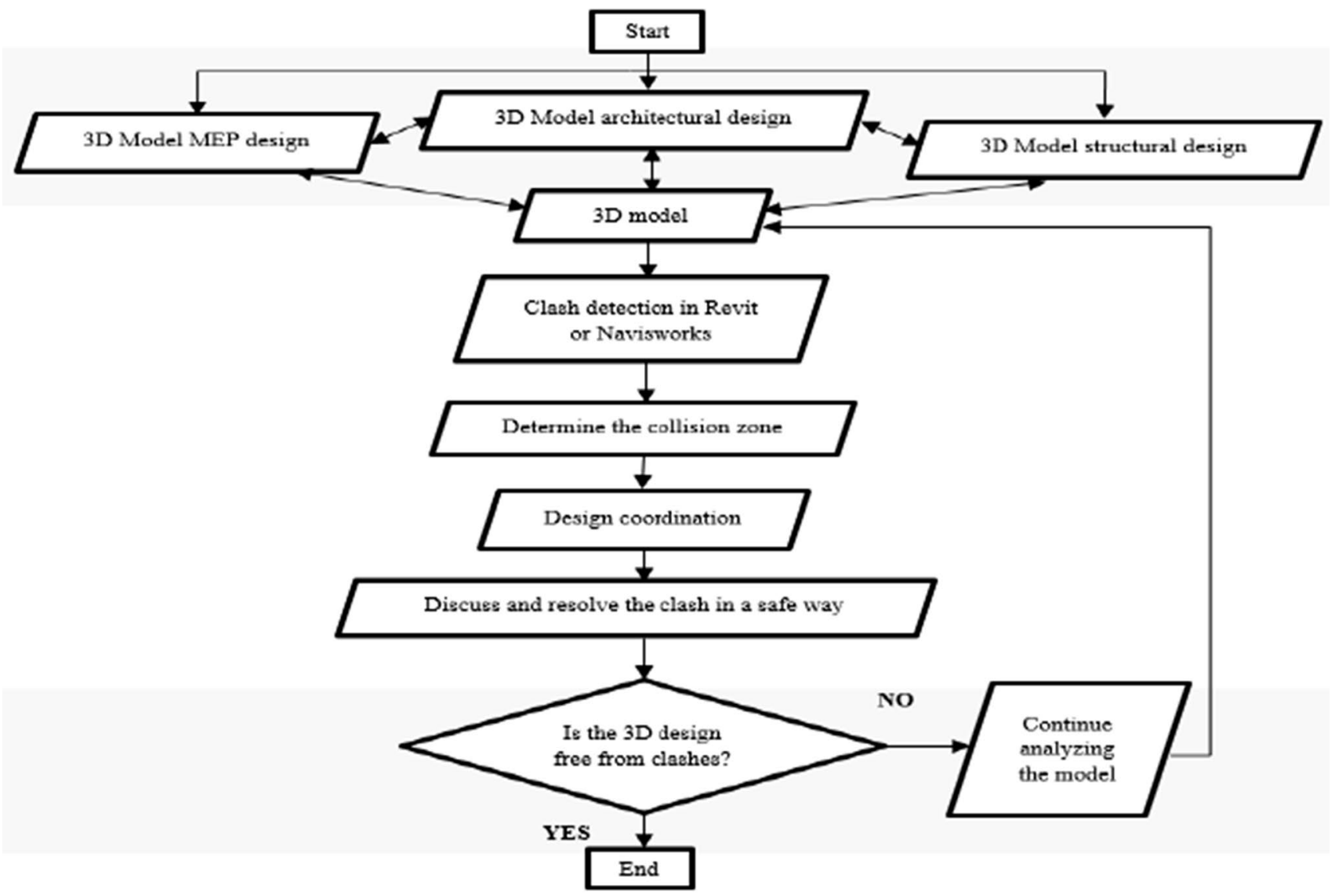

Fig. 4 The BIM methodology to reduce conflicts between the designer's work (architectural, structural, and MEP) 
addition to providing visual verification that allows all project members, especially the owner, to walk around and see the components of the virtual model. Consequently, change orders are reduced during the early stages of the project and before the construction process begins, as shown in Fig. 5, which shows the difference between the CAD and BIM systems.

The BIM model can extract all facades, horizontal levels, vertical sectors, architectural and non-architectural details of the building and provide all design-related information, such as areas, volumes, finishes schedules, stock schedules, and quantities, in addition to a project implementation schedule.

The Building Information Visual Communication feature in BIM allows the owner to roam the building in 3D and discover the building as a whole in terms of spaces, elements, and materials used, generate conditions necessary to understand the project, and supply materials for building components. This information within the 3D visual model, which displays more detail than can be imagined, contributes to reducing the need for element questions in terms of specifications and component materials, which fulfills the owner's requirements very efficiently by implementing the changes he issues to the default model in the design stage, which leads to reducing the change orders owed to the owner during the implementation phase.

Figure 6 provides a diagram of the sequence of steps in making a 3D design model using BIM functions in the design stage to reduce construction claims resulting from the design change by the owner that leads to lowering excessive change order by the owner during the construction phase.

\section{BIM preventive approach for (quantitative Inaccuracies) and (variations between original and actual quantities)}

It is well recognized that quantity calculations play an important role in the project life cycle, beginning with project design and continuing through execution until the project is turned over to the owner. They play a significant role in deciding the project's time, expense, and quality standards.
There are several programs specialized in calculating quantities that deal with the charts either in electronic or paper form, including Autodesk Quantity Take-off, which is specialized in calculating amounts and dealing with two-dimensional electronic maps, as well as the AutoQTY program specialized in quantities calculation and cost estimation in addition to the famous On-Screen Takeoff program for calculating quantities and reading data of the two-dimensional diagrams. Several other popular programs for calculating quantities, including Win QS, CostX, U QTO, Q.S. Plus, and Easy Tender and other software specialized in quantities calculation.

The Excel program is also used, especially at the local level, to calculate quantities, as it is an easy and available tool. Equations, inputs, and outputs are formed according to the person's desire for estimating quantities and costs, and the process is done manually. Through the architectural, structural, mechanical, electrical, and sanitary plans, quantities are calculated for the building separately. If any modification is made to the design plans, this is not reflected in the quantities calculated. Therefore, the possibility of omissions and errors using the Excel program is very likely, in addition to wasting time and effort spent.

The BIM technique came with its new technologies to solve the inaccuracy of quantities during the project's design stage using Autodesk Rivet, Navisworkws, and the BIM technology's 3D visualization and coordination function. with Revit, it is possible to extract quantities for the modeled building elements. The BIM model contains all the building elements that have been assembled through the architectural, structural, mechanical, electrical, and sanitary models of the same building in one model. Among the advantages of the Revit program in calculating quantities:

- Visual verification of a particular element and knowing its exact quantity is easy.

- As the model changes, such as modifying parts or materials, the amendment is made directly to the bill of quantities.

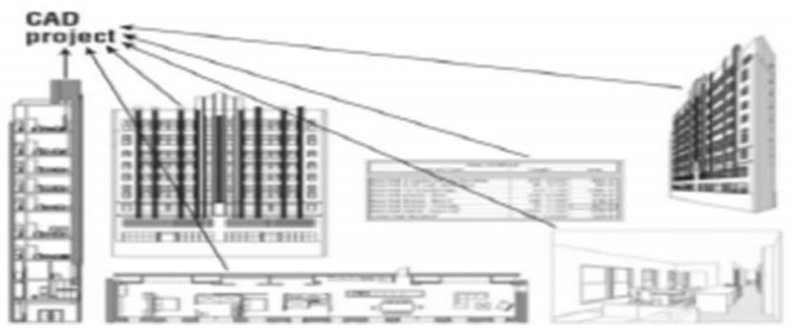

Fig. 5 Comparison of work style in CAD and BIM systems [16] 


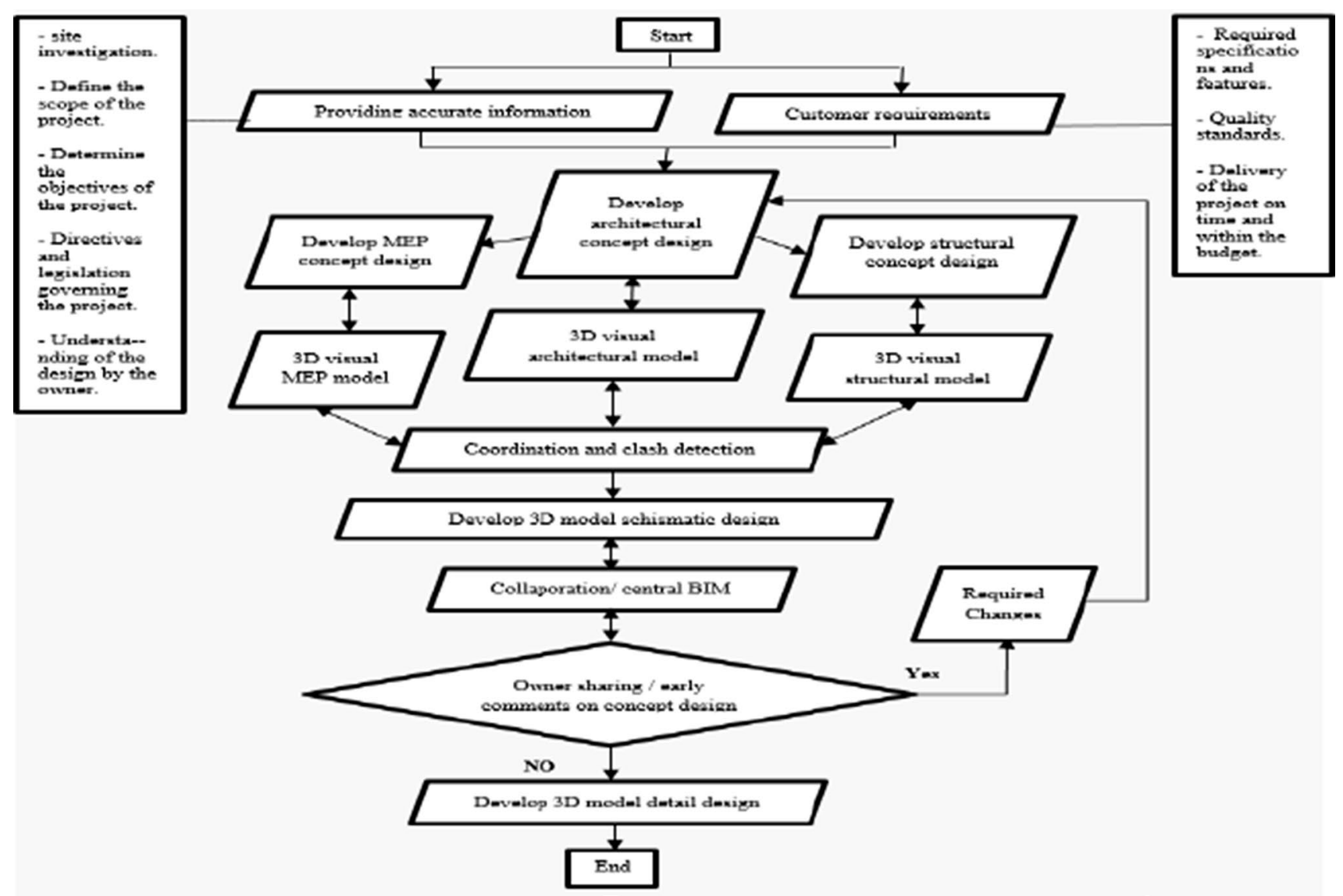

Fig. 6 The BIM methodology to reduce design change and excessive change order by the owner

- The project quantities can be completely measured according to the object classification with only one press, and it will only take a few minutes.

- When analyzing costs, make a list of products, labor, and equipment. Knowing how it affects an object's price allows you to negotiate different options with the owner from an economic standpoint.

- The format of the tables can be formatted using bills of quantities exported to Excel.

Figure 7 provides a diagram for the sequence of quantities calculation steps using BIM functions in the design phase and their output with high accuracy to reduce construction claims resulting from the inaccuracy of quantities during the design phase. Simultaneously, the variation between the planned and real quantities during the construction phase will be prevented.

\section{Real case study}

The project (Building a primary school with 18 classrooms) is located in Al-Tamim District / Al-Muthanna Governorate / Al-Samawah District/ Republic of Iraq. The project implementation period is (420) days, and the total cost is $(1,559,330,500)$ I.D. The BIM was applied to the case study project through Revit 2020 and Navisworks 2020, as shown in Fig. 8.

The BIM was applied to the case study used in the research through the Revit 2020 and Navisworks 2020, while Excel 2016 programs and the AutoCAD 2020 program will convert the school's plans from the PDF format to the AutoCAD drawing.

The Revit program will be used to make 3D architectural, structural, and sanitary models and coordinate between all disciplines to integrate them into a unified model. The Revit program was also used to solve interdisciplinary clashes (architectural, structural, and MEP) exported as reports from the Nevisworks program.

Navisworks program will be used to extract reports of clashes between all disciplines (Architectural, Structural, and MEP) by linking it with the Revit program and then extracting quantification and quantifying it in the project and exporting quantity take-off reports after completing them to the Excel program.

Due to the large number of data (family) used in the project, for example, the presence of a large number of columns. 


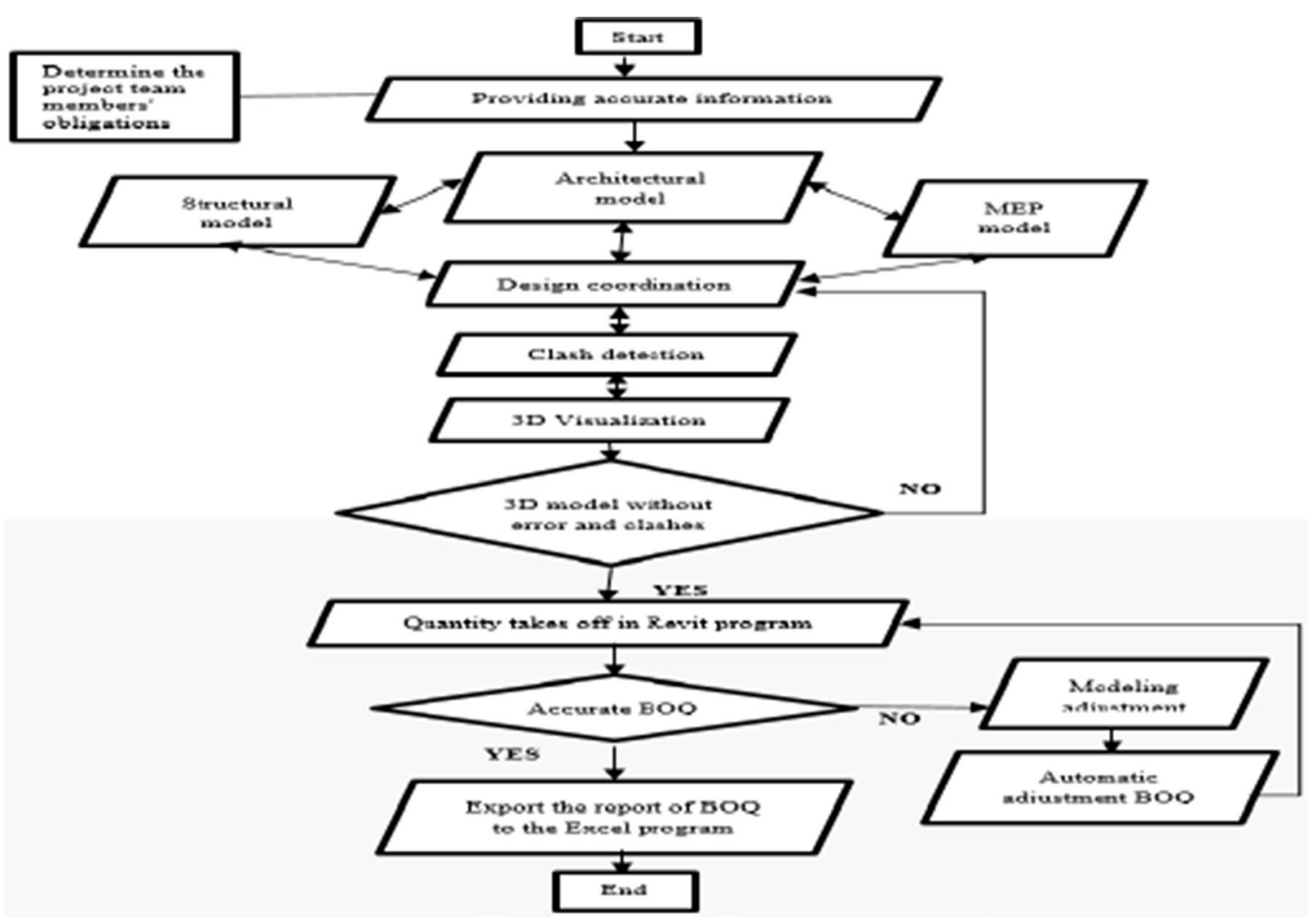

Fig. 7 The BIM methodology to reduce inaccuracy of quantities

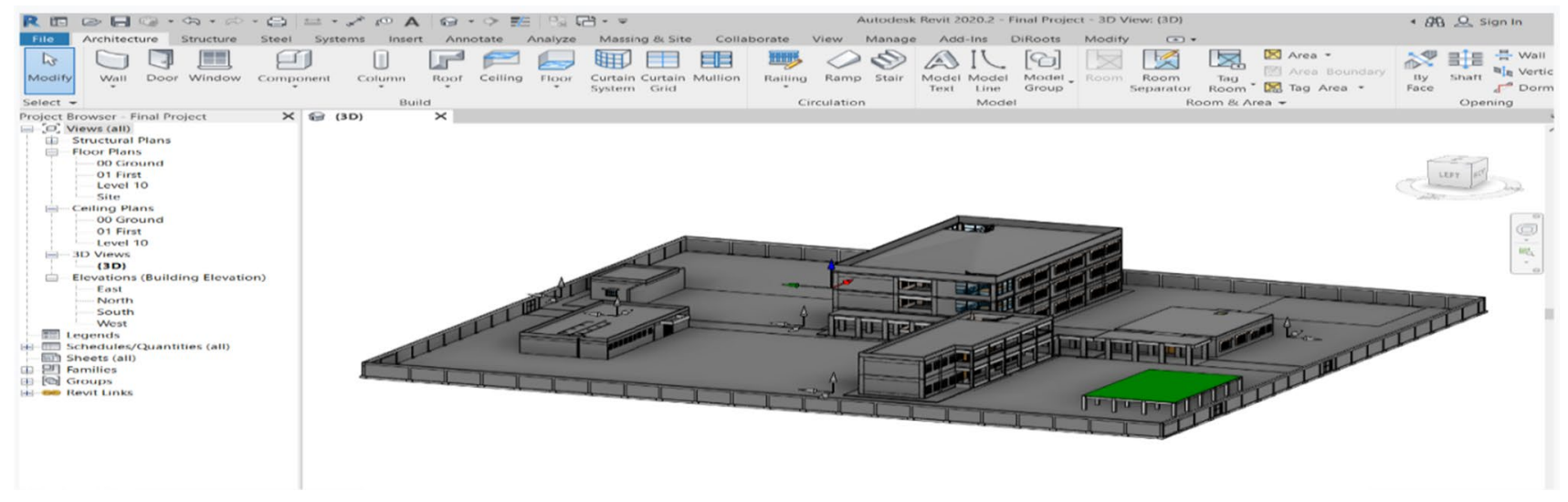

Fig. 8 A 3D architectural, structural, and MEP model (Revit interface)

Instead of writing them manually in the Revit program. The researcher used the Excel version 2016 program to enter that data and then export it to the Revit program to note that data in a shorter time.

Furthermore, take-off quantities reports were exported from the Navisworks program to the Excel program to extract them in tables of quantities.

The AutoCAD program, the 2020 version of the twodimensional graphic and engineering programs. The
Ministry of Education (the beneficiary of the project) has relied on the AutoCAD program in the case study's design work approved in the research. The project plans in PDF formats were obtained, so the AutoCAD program needed to convert those plans from PDF to CAD drawings and export them to the Revit program.

BIM programs applied to the case study in three stages as follows: 


\section{D visual model of the case study using BIM}

The Revit has been used to prepare the architectural model separately, followed by the structural and MEP models. Weakness in the design team's obligations, including (poor designer's perception and poor use of advanced computer programs), and failure to meet the customer's requirements regarding the accuracy of specifications and features, led to claims.

In this stage, the causes of the claims, which include (lack of drawings and specifications, design errors, changes in design and specifications, and change orders), were revealed and resolved using the BIM function (3D visualization) in the design phase. This job reduced the cost of claims by $50,519,000$ ID and the time by 87 days. That claims will be analyzed as follows:

- The wooden doors' description in the doors description table did not match the drawings' description and symbols in the projections and the facades; claims for increased cost and duration arose during the project's construction phase due to those defects in the door and windows specifications that led to the change order's issuance.
- Design errors were detected in the stairs' drawings and specifications; the mismatch between the floors' height in the building and the number of stairs in the architectural and structural plans; there are also openings between floors and stairs, as shown in Fig. 9.

This error led to claims that increased the cost and duration of the project during the implementation phase. It ended with amending the stairs' designs and issuing change orders. In Fig. 10, the error has been corrected during the modeling process in the project design phase by increasing the number of stairs bytes to (20) and adjusting the height and dimensions of the stairs by making use of the three-dimensional visualization function that enabled the designer to notice this error and solve it quickly during the design phase to reduce this claim at the implementation stage.

- Due to the lack of perception of the owner, two paragraphs were introduced during the implementation phase, including the iron quarry for covering the walls of the corridors for the first and second floors to protect students and the paragraph for adding windows to the stairwell, which led to the occurrence of claims to increase the cost and duration of the project by issuing the change order.

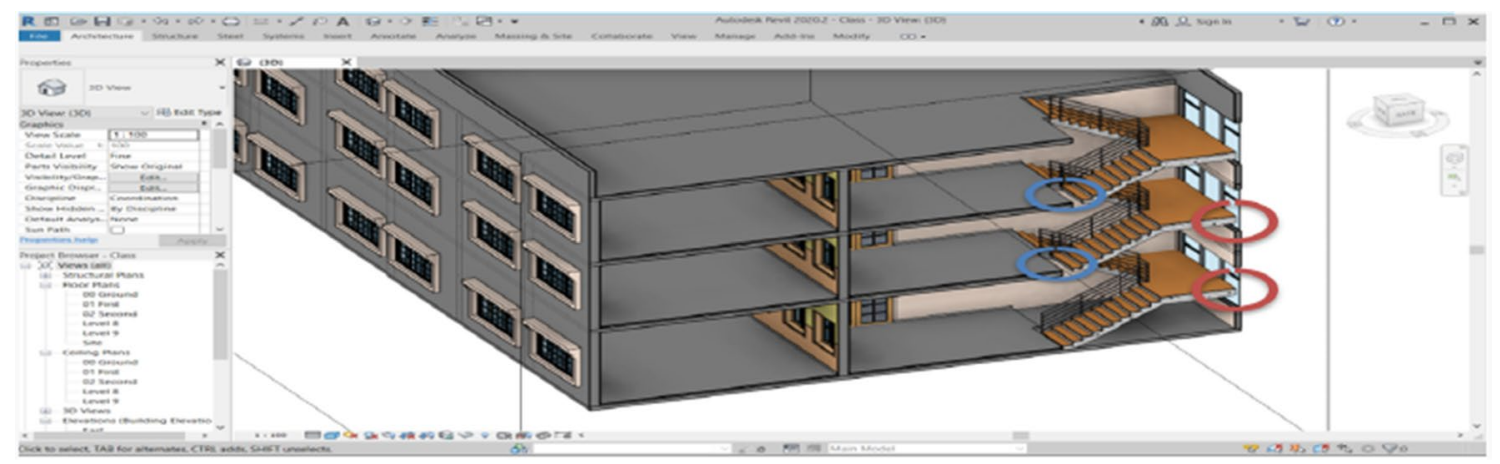

Fig. 9 Cross section of the project (error in the stairs drawings)

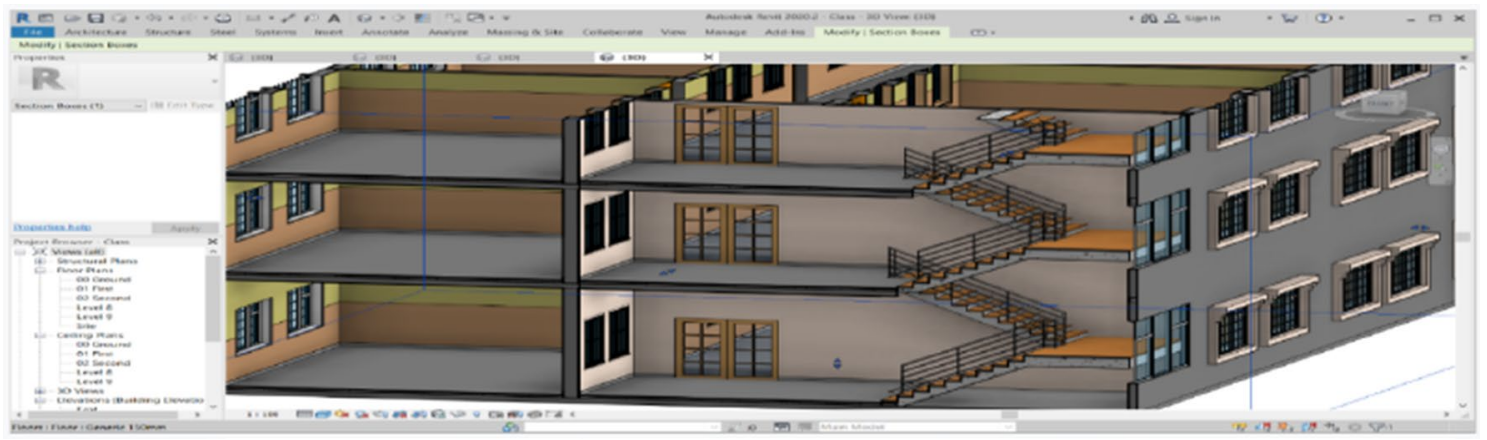

Fig. 10 Cross section of the project after solving errors in the stairs drawings 
- During the implementation phase, the specifications of the pipes were changed by the designer for the sanitary works in the project by changing the type from the steel type to the plastic-type, which led to claims for the leadership of the project cost, as shown in Fig. 11.

- When the project was implemented, the owner issued a change order due to the poor visualization by adding the tiles for the covered link corridor floors and the school's entrance. With the introduction of the building clause with bricks, the school needs a wall, which led to claims for an increase in the project's cost and duration

\section{Clash detection and coordination for a case study using BIM}

The Revit and Navisworks programs were used to coordinate a unified project model (integrating the architectural, structural, and MEP model into one) to detect and resolve conflicts. At this stage, it was found that the weakness of the design team's obligations (lack of communication, misuse of advanced computer programs) leads to allegations, as the two BIM functions (coordination and clash detection) were used to detect and reduce the claims involved (lack of coordination between engineering disciplines (Architectural, Structural, MEP), design errors, design change, and change orders) through lowering the cost and duration of claims by 41,504,500 DI and 94 days, respectively. These claims will be analyzed as follows:

- Structural beams and walls clash: contain one hundred and six clashes in different locations, as shown in Fig. 12.

Using traditional methods, most of these clashes were detected during the project implementation phase. The solution was to modify the architectural plans and introduce the walls to the beam projections, which led to claims for the increased project duration. The other part of the clashes was revealed after the execution. The solution was to encapsulate the building's front facades to cover this outcrop, which led to claims between the parties to increase the project's cost and duration.

- The floors and structural foundations clash: contains fourteen clashes in different locations, as shown in Fig. 13.

When implementing the project using traditional methods, a clash appeared between the structural foundations and the floors, leading to the emergence of claims to increase the project's cost and duration. The solution was to issue change orders to add the quantity of burial underground to raise the floor level to not conflict with the foundations.

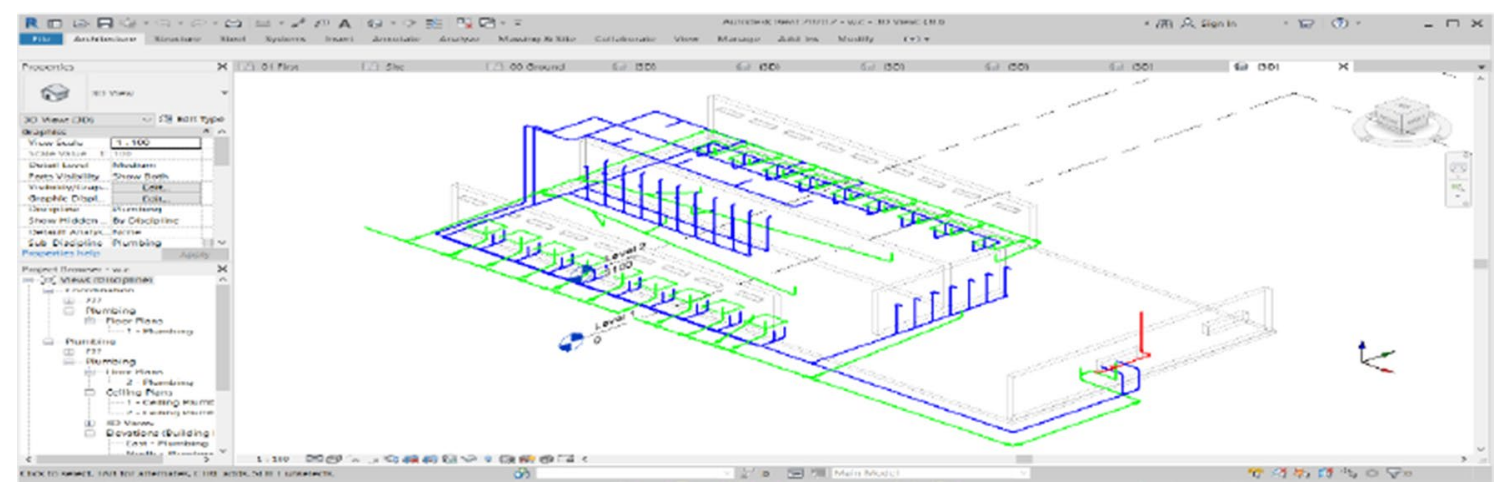

Fig. 11 MEP model

Fig. 12 Clash detection between structural beams and walls

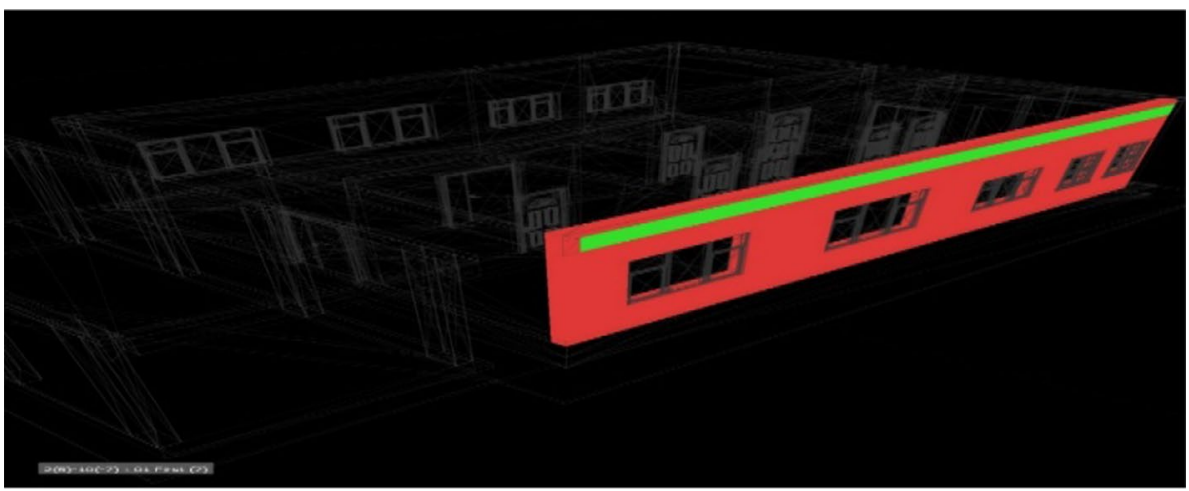


Fig. 13 Clash detection between the floors and structural foundations
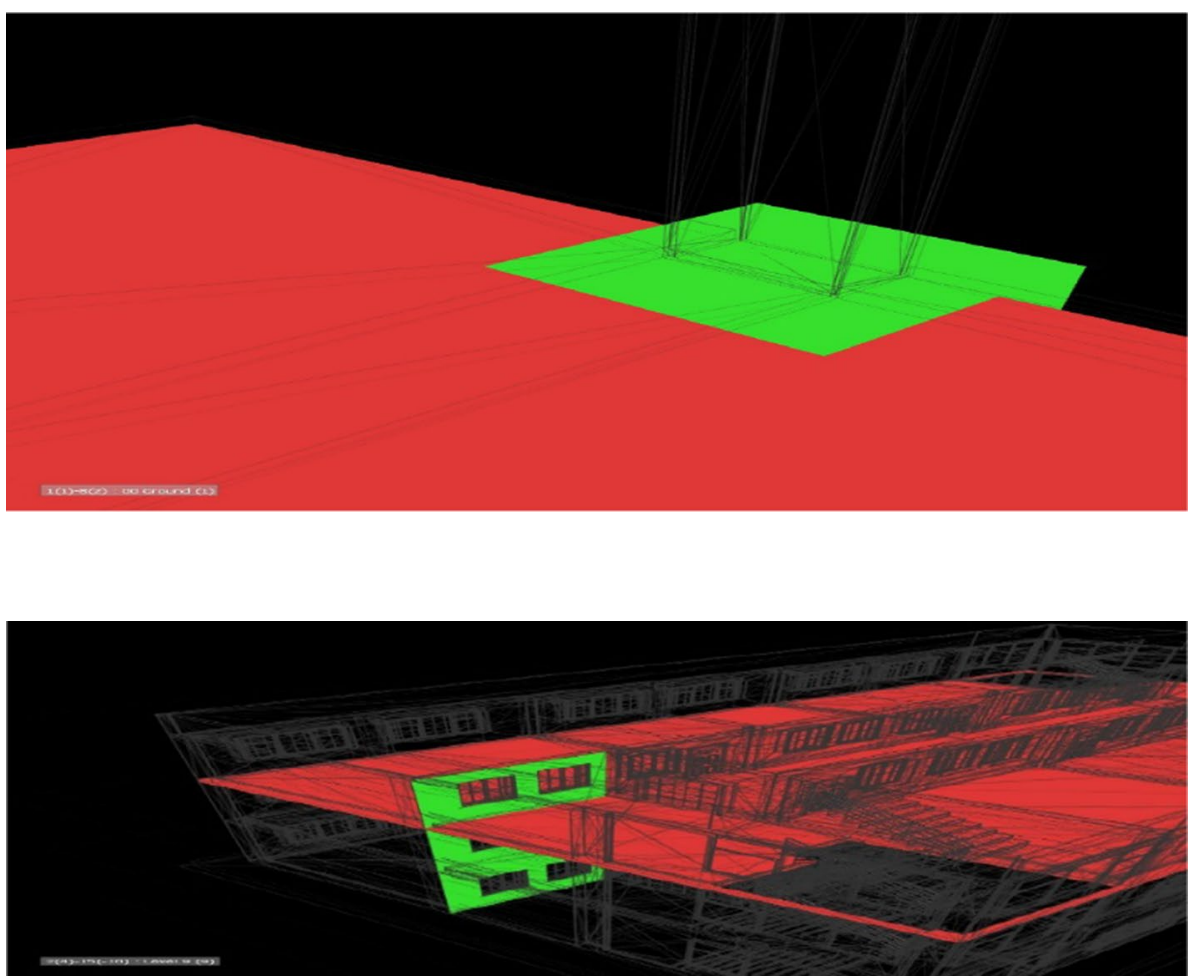

Fig. 14 Clash detection between the floors and walls

Fig. 15 Clash detection between the windows and structural framing

Fig. 16 Clash detection between the structural columns and stairs and windows
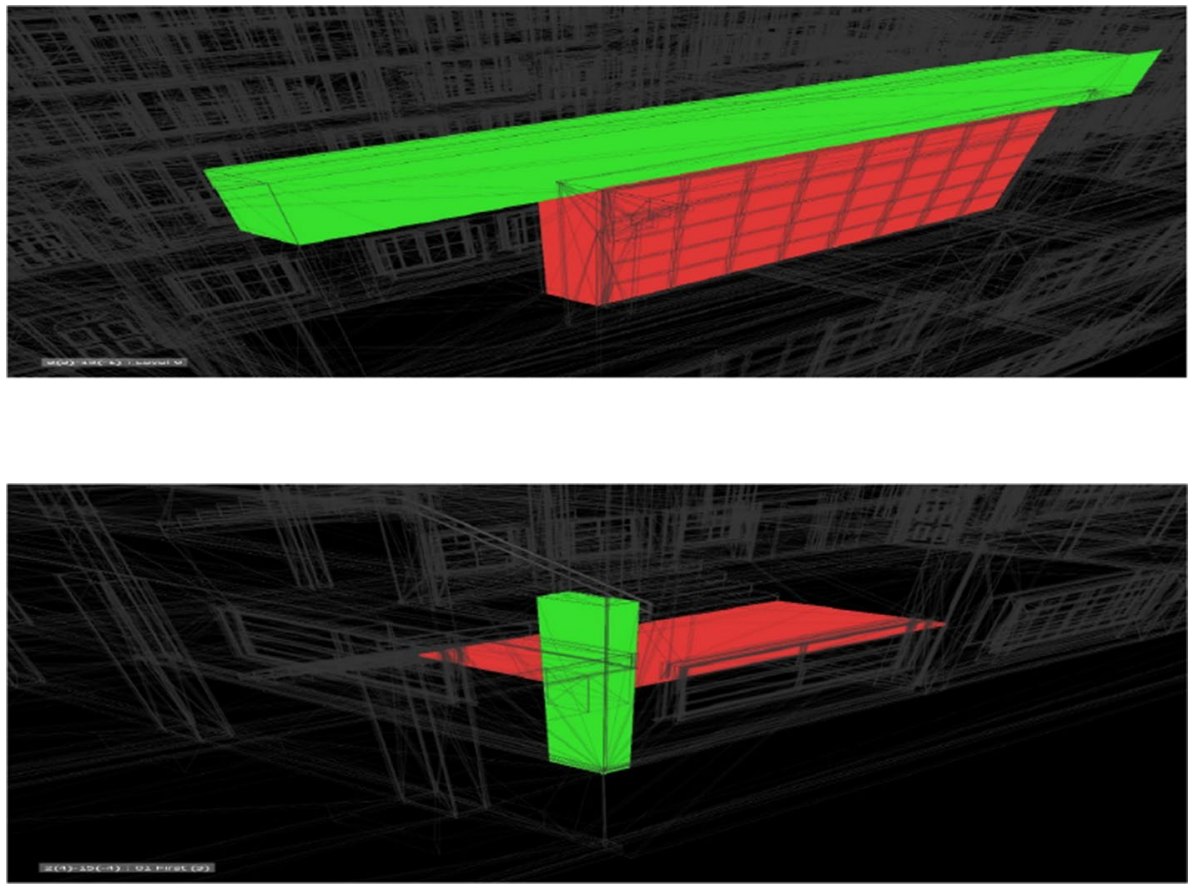

- The floors and walls clash: contains ninety-nine clashes in different locations, as shown in Fig. 14.

- The windows and structural framing clash: contains thirty clashes in different locations, as shown in Fig. 15.

During the project's implementation, using traditional methods, it was noticed that there was a clash between the windows and the structural beams. The solution was to modify the structural plans and converting the fallen beams into upside-down beams, which led to the emergence of claims to increase the project's cost and duration.

- The structural columns \& stairs, and windows clash: contains six clashes in different locations, as shown in Fig. 16. 
During the project's implementation by using traditional methods, it was noticed that there was a clash between the windows and the structural stairs. The solution was to change the windows to become the fixed type and not openable, which led to the emergence of claims to increase the project cost.

- Pipes and structural foundations clash: contains three hundred and ninety clashes in different locations, as shown in Fig. 17.

During the implementation by traditional methods, the clash between the pipes and the structural foundations appeared. The solution was to raise the pipes' slope, which led to claims for a design change and an increase in the project's cost and duration.

\section{Quantity take-off for a case study using BIM}

In the previous stages, after performed the correct modeling of the project and revealed and resolved all the interdisciplinary clashes, the case study's 3D model became prepared for counting quantities with high accuracy using the Revit program. In this stage, it was found that the design team's obligations were weak (misuse of advanced computer programs) that resulted in claims being created.

The accuracy of the quantities calculated using BIM and the traditional method used in a case study was verified by applying Eq. (1).

$A \%=100 \%-\frac{\left(\sum_{1}^{n} \frac{|\mathrm{Si}-\mathrm{Gi}|}{\mathrm{Gi}} \times 100\right)}{n}$

where $(A \%)$ : The Accuracy Percentage, $(\mathrm{Si})$ : The quantity take-off by using BIM or tender, (Gi): The quantity as-built, $(n)$ : The total number of items.

Claims for (quantities inaccuracy, difference between planned and realistic quantities) will be solved depending on the BIM functions (3D visualization, coordination, clash detection, and take-off quantities). It was found the accuracy of quantities take-off in BIM (95\%), which is more than accuracy for the bill of quantities in traditional methods
( $82 \%)$ that led to issuing change orders by adding quantities of (54,860,500 ID) and deleting amounts of (26,848,000 ID) and delay 13 days because of inaccuracy in calculating quantities.

\section{Results}

The results of matching experts' opinions and real projects showed 16 reasons for construction claims in Iraq. The matching BIM functionality results with these reasons also showed eight reasons BIM technology can avoid during the design phase to serve as a preventive approach to claims and resolve them during the design phase before project implementation. Lead to reducing claims on construction projects in Iraq.

A case study (a project to build a three-story school of 18 classrooms) was choosen to apply the BIM functions during the design phase, since this project contains almost the most important causes of the claims above, and the results showed the following:

- The reasons (the inaccuracy of quantities due to the consultant during the design phase) and (the difference between the realistic and amounts planned due to the consultant during the implementation phase) can be reduced during the design phase depending on the BIM functions (3D model, coordination, clash detection, and quantity take-off) so that the results showed that the accuracy of BIM in counting the quantities was (95\%). In comparison, the traditional method was (82\%), which led to a reduction of the cost by $(28,012,500$ ID), and the duration of the project is about (10 days).

- The BIM functions (3D visualization, structural analysis, clash detection, and coordination) applied to the case study during the design phase were able to solve the reasons (deficiencies or error in the design, drawings, or specifications due to the designer during the design phase) and (design changes by the designer during the implementation phase) by reducing the cost and duration of the project, respectively, by (34,240,000 ID) and (128 days).
Fig. 17 Clash detection between the pipes and structural foundations

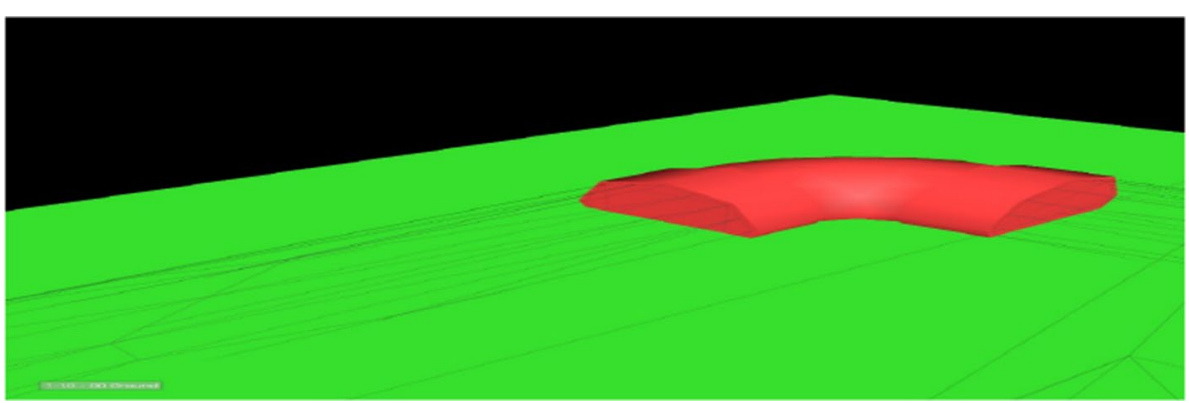


- The results of using BIM functions (3D visualization, clash detection, coordination) on the case study also showed its ability to reduce the cause (Poor coordination between consultants (architectural, structural, and MEP) during the design phase) at early stages during the design, which led to a reduction in the effects of that cause represented by the cost and duration of the project, respectively (40,705,000 ID) (41 days).

- (Changing the design by the owner during the design phase) The BIM can solve it through the 3D visualization and collaboration between the parties, which leads to reducing the frequent change of orders due to the owner during the implementation phase. This was demonstrated during the application of BIM to the study situation that reduced the effects of those reasons represented by the cost (17,079,000 ID) and the period (15 days).

- The results indicate that the application of BIM functions led to a decrease in the cost of claims by $(57.2 \%)$, the time of claims by $(53.2 \%)$, Thus reducing claims by $(55.2 \%)$.

\section{Conclusion}

The main reason for claims in most construction projects in Iraq is the project parties (owner, consultant, and contractor). The impact of claims on cost and time overruns for construction projects is very high. This confirms that there is no real system in most construction projects in Iraq to manage claims. In addition to the lack of clarity of vision for engineers regarding the administration of construction claims and those responsible for managing them. Most of the major causes of building project claims can be resolved during the design stage, thus minimizing their occurrence.

The study confirmed that it is possible to apply BIM and use its functions (3D visualization, clash detection, coordination, and quantities take-off) during the design phase to reduce the claims resulting from (omissions or errors in design, changes in design, discrepancies in specifications and drawings, poor coordination and communication between designers (structural, architectural and MEP), owner change orders, and inaccuracy of quantities) and thus reduce their occurrence during the project implementation phase by $55.2 \%$. BIM simplifies the claims management process by identifying potential claims, information consistency, data storage, and improved collaboration.

The study recommends the necessity of relying on advanced technologies, means of communication, and advanced computer programs in the Iraqi construction projects that will reduce the chances of claims occurrence. And applying the proposed preventive approach in using BIM during the design phase and providing the necessary financial allocations for its use to reduce claims on construction projects in Iraq.

Acknowledgements This paper was produced in cooperation with the Department of Civil Engineering/ University of Baghdad.

\section{Declarations}

Conflict of interest On behalf of all authors, the corresponding author states that there is no conflict of interest.

\section{References}

1. Abdul-Malak MAU, El-Saadi MMH, Abou-Zeid MG (2002) Process model for administrating construction claims. J Manag Eng 18(2):84-94

2. Stojadinovic Z (2018) Claims on construction projects-quantification and prevention. In: Proceedings of conference contemporary construction practices. pp 83-112. https://www.researchgate. net/publication/325846239_CLAIMS_ON_CONSTRUCTION_ PROJECTS-QUANTIFICATION_AND_PREVENTION

3. Alshdiefat A (2013) Evaluation of claims management, causes, impacts and resolution in building projects in Jordan. MSc Thesis, Al Isra University, Jordan

4. Hadi IZ (2018) Building a management system to control the construction claims in Iraq. Al-Khwarizmi Eng J 14(1):108-117. https://doi.org/10.22153/10.22153/kej.2018.08.004

5. Love P, Davis P, Ellis J, Cheung SO (2010) Dispute causation: identification of pathogenic influences in construction. Eng Constr Archit Manag 17(4):404-423

6. Brooker P, Lavers A (1997) Perceptions of alternative dispute resolution as constraints upon its use in the UK construction industry. Constr Manag Econ 15(6):519-526

7. Al-Zwainy FMS, Jaber FK, Hachem SW (2018) Diagnostic of the claims and disputes between the contractor and owner in construction project using narrative analysis approach. Int J Civ Eng Technol 9(12):619-626

8. Ali B, Zahoor H, Nasir AR, Maqsoom A, Khan RWA, Mazher KM (2020) BIM-based claims management system: a centralized information repository for extension of time claims. Autom Constr 110:102937

9. Jalal MP, Roushan TY, Noorzai E, Alizadeh M (2020) A BIMbased construction claim management model for early identification and visualization of claims. Smart Sustain Built Environ 10(2):227-257

10. Mahdi MM, Wali KI, Yuosif BA (2020) Minimizing time and cost in the Iraqi AEC industry by adopting building information modeling (BIM) technique. Zanco J Pure Appl Sci 32(6):185-196

11. Dastyar B, Esfahani AF, Askarifard M, Abbasi AM (2018) Identification, prioritization and management of construction project claims. J Eng Proj Prod Manag 8(2):90-96

12. Khoshnava SM, Ahankoob A, Preece C, Rostami R (2012) Potential application of BIM in construction dispute and conflict. Conference: Management in Construction Research Association Postgraduate Conference 2012At: Universiti Teknologi Malaysia Kuala Lumpur. https://www.researchgate.net/publication/26898 0388_Potential_Application_of_BIM_in_Construction_Dispute_ and Conflict

13. Bakhary NA, Adnan H, Ibrahim A (2015) A study of construction claim management problems in Malaysia. Procedia Econ Finance 23:63-70 
14. Chou J-S, Hsu S-C, Lin C-W, Chang Y-C (2016) Classifying influential information to discover rule sets for project disputes and possible resolutions. Int J Proj Manag 34(8):1706-1716

15. Ibraheem RAR, Mahjoob AMR (2021) Exploring the causes of claims during the project life cycle in the Iraqi construction sector. Des Eng 2021(4):382-400
16. Vandezande J, Read P, Krygiel E (2011) Mastering autodesk revit architecture 2012. Wiley, Hoboken

17. Rasheed RH, Rezouki SE (2012) Application of geographic information system for preparing the bill of quantities of construction projects. J Eng 18(8):979-988 